\title{
An Enhancement of Plasma Density by Neutral Gas Injection Observed in SEPAC Spacelab-1 Experiment
}

\author{
S. SASAKI ${ }^{1}$, S. Kubota ${ }^{2}$, N. KaWAShima ${ }^{1}$, K. Kuriki ${ }^{1}$, M. Yanagisawa ${ }^{1}$, \\ T. Obayashi ${ }^{1}$, W. T. Roberts ${ }^{3}$, D. L. Reasoner ${ }^{3}$, W. W. L. TAYlor ${ }^{4}$, \\ P. R. Williamson ${ }^{5}$, P. M. BANKS ${ }^{5}$, and J. L. BURCH \\ ${ }^{1}$ The Institute of Space and Astronautical Science, Tokyo, Japan \\ ${ }^{2}$ The University of Electro-Communications, Tokyo, Japan \\ ${ }^{3}$ NASA Marshall Space Flight Center, Alabama, U.S.A. \\ ${ }^{4}$ TRW Space and Technology Group, California, U.S.A. \\ ${ }^{5}$ Stanford University, California, U.S.A. \\ ${ }^{6}$ Southwest Research Institute, Texas, U.S.A.
}

(Received February 12, 1985; Revised April 23, 1985)

\begin{abstract}
An enhancement of plasma density observed during a neutral gas injection in Space Experiments with Particle Accelerators: SEPAC by the Space Shuttle/Spacelab-1 is presented. When a plume of nitrogen gas was injected from the orbiter into space, a large amount of plasma was detected by an onboard plasma probe. The observed density often increased beyond the background plasma density and was strongly dependent on the attitude of the orbiter with respect to the velocity vector. This effect has been explained by a collisional interaction between the injected gas molecules and the ionospheric ions relatively drifting at the orbital speed.
\end{abstract}

\section{Introduction}

Space Experiments with Particle Accelerators (SEPAC) was carried out by the Spacelab-1, STS 9 mission in 1983 (OBAYASHI, 1984). The major purpose of the experiment was to perform an active experiment in space using a high power electron beam accelerator and magneto-plasma-dynamic arcjet. A neutral gas plume injector was also onboard for the purpose to neutralize the charging effect of the orbiter during the electron beam emission.

During the Spacelab-1 mission, gas injection experiment without the electron beam emission was carried out five times in night time in different flight configurations. The gas injector is able to inject $10^{23}$ nitrogen molecules during 100 msec into space from the Spacelab pallet. Synchronized with the gas injection, a considerable amount of plasma was unexpectedly detected by an onboard plasma probe quite often.

Initially, this phenomenon was believed to be a kind of gas ionization in which the gas molecules are ionized by hot electrons produced by a wave-particle interaction (SASAKI et al., 1984). Further investigation has revealed that this ef- 
fect is to be explained by collisional interaction between the ionospheric ions and the gas plume molecules. The collisional interaction has been also reported by KATZ et al. (1984) in relation to the polarization effect of plasma surrounding the orbiter. Our present paper presents a further analysis result of the gas injection experiment and gives a possible mechanism for the enhancement of the plasma density detected during the gas injection.

\section{Experimental Results}

The gas is injected through a cone-type laval nozzle with $20 \mathrm{~mm}$ in exit diameter which is assembled in the plasma accelerator (MPD). The estimated profile of the gas density in front of the gas nozzle is shown in Fig. 1. The cone angle of the gas plume is about 40 degrees (half angle). The diagnostics onboard the pallet are floating probes, Langmuir probe, electron energy analyzer, photometer, vacuum gauge and VLF $(0.75-10 \mathrm{kHz}) / \mathrm{HF}(100 \mathrm{kHz}-10 \mathrm{MHz})$ wave receivers. They are assembled in a package (DGP) and located below the gas injector. The configuration of these instruments on the pallet is shown in Fig. 2.

A cylindrical probe with electrode surface of $25 \mathrm{~cm}^{2}$ is used as the Langmuir probe. The bias voltage is either swept from $-9 \mathrm{~V}$ to $+9 \mathrm{~V}$ in $84 \mathrm{msec}$ (sweep mode) or fixed at a certain positive voltage (fixed mode). The vacuum gauge measures the gas pressure from $5 \times 10^{-8}$ to $5 \times 10^{-4}$ Torr with a response of

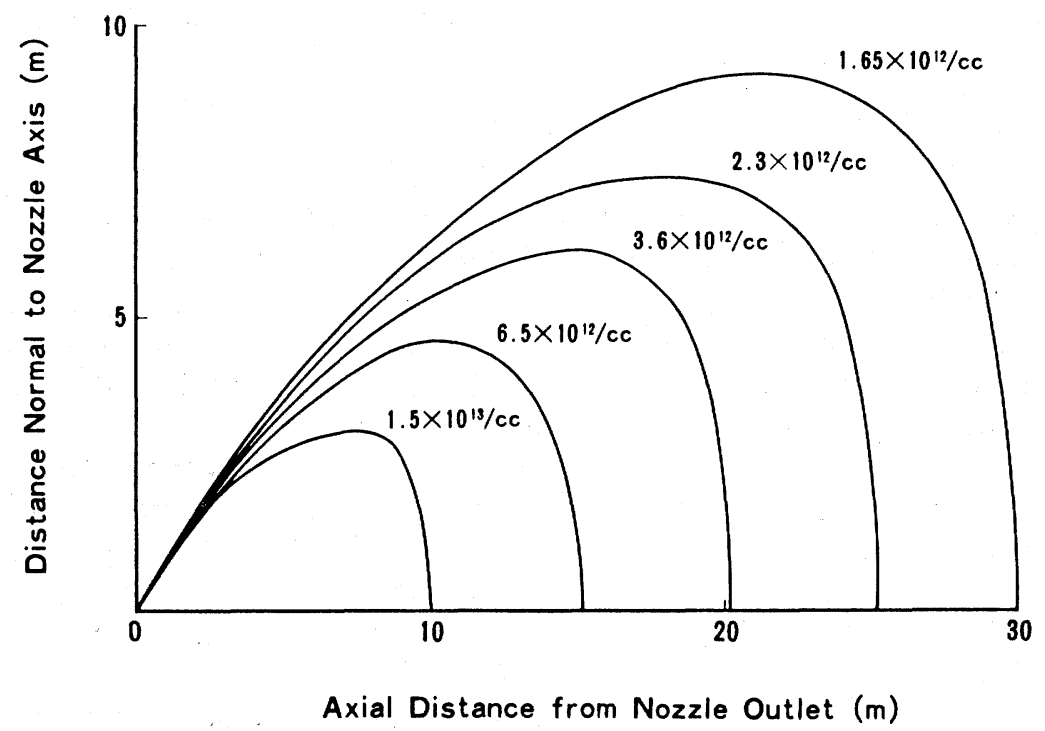

Fig. 1. Density profile of nitrogen gas ejected from SEPAC neutral gas plume injector. $10^{23}$ molecules are injected during $100 \mathrm{msec}$. 


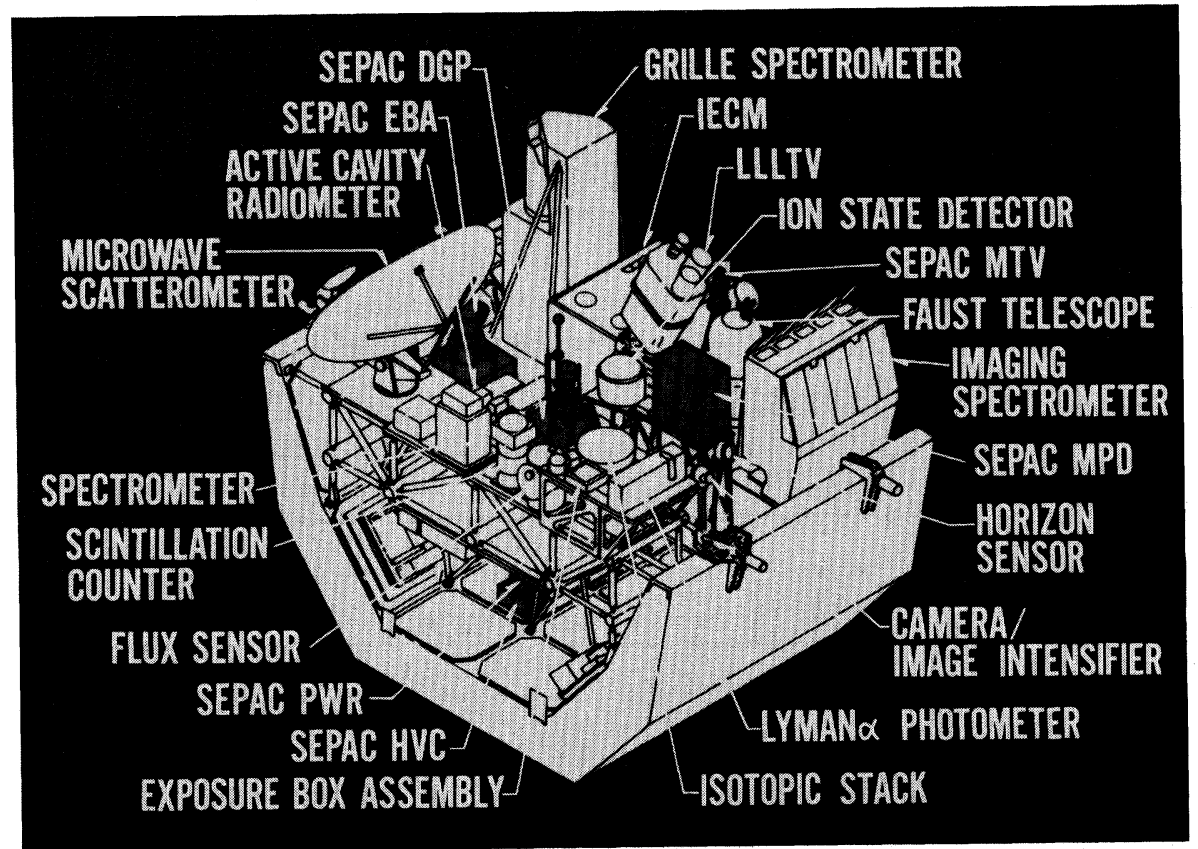

Fig. 2. Configuration of the pallet instruments. Shaded instruments belong to SEPAC. Neutral gas is injected from MPD straight upwards with respect to the pallet. DGP is a diagnostic package composing of floating probes, Langmuir probe, photometer, vacuum gauge and wave receivers.

$1 \mathrm{msec}$. The photometer is equipped with three filters $(3914,5577,6300 \AA)$ of which measurable range is from $10^{-13}$ to $5 \times 10^{-10}$ watt. The antenna of the VLF wave receiver is a monopole type with high impedance (potential sensor). The measurable frequency ranges from $750 \mathrm{~Hz}$ to $10 \mathrm{kHz}$.

The pressure measured by the vacuum gauge was $(1.0-1.2) \times 10^{-6}$ Torr before the gas injection. This pressure which is higher by about one order than the standard ionosphere model is attributed to the outgassing effect from the surrounding instruments. When the gas plume was injected, the pressure measured by the gauge located below the gas injector increased up to $(2-3) \times 10^{-6}$ Torr. This is due to the gas molecules scattered by the surrounding Spacelab structure and entering into the gauge. The background plasma density measured by the Langmuir probe was $1 \times 10^{4} / \mathrm{cc}$ or less, which is much less than the standard ionospheric plasma density. The great reduction of the plasma density at the probe which is located near the bottom of the pallet is caused by the wake effect. When the gas plume was injected, the current of the Langmuir probe increased by up to 150 times of the initial level. The typical examples in which the probe bias was fixed at $9 \mathrm{~V}$ are shown in Fig. 3. The Langmuir current increased in 20-30 msec (rising phase), kept almost constant level for 90-100 msec (cons- 


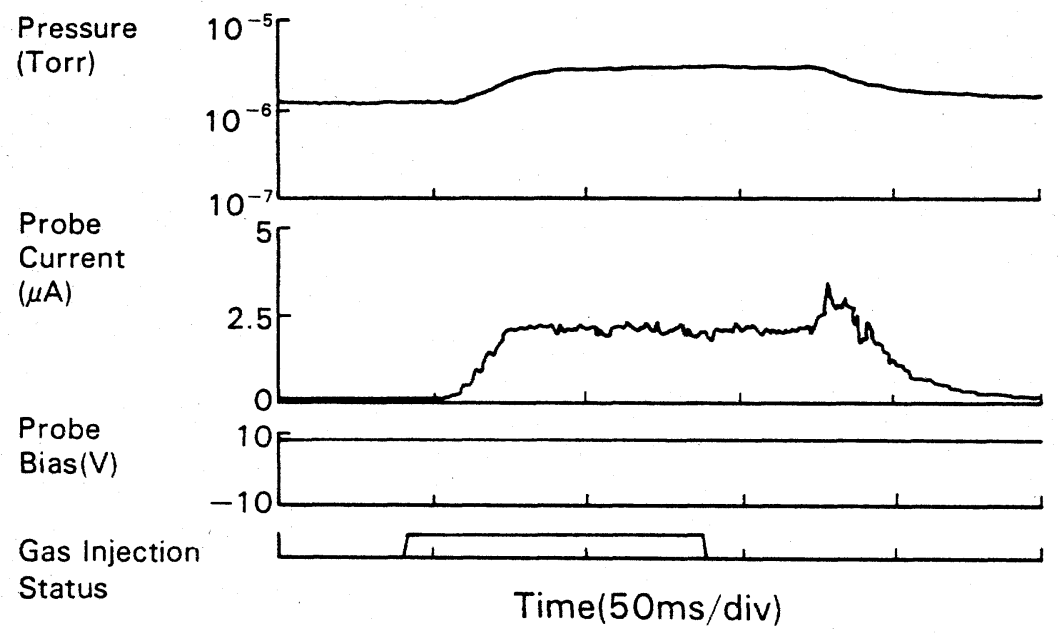

(a)

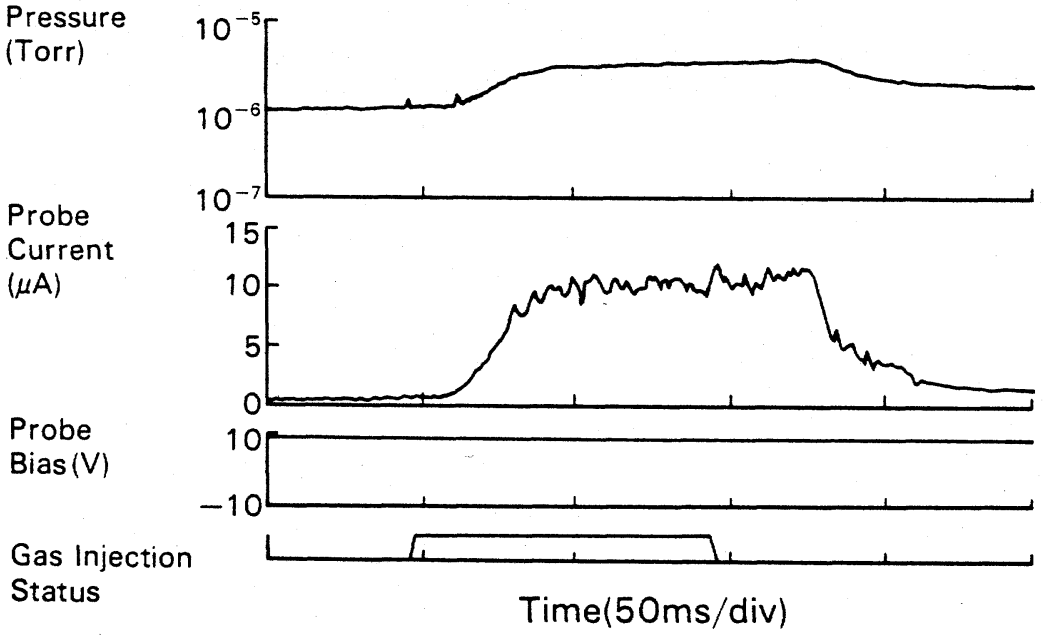

(b)

Fig. 3. Examples of the probe current enhancement during the gas injection. The Langmuir current increases together with the pressure after the start of the gas injection. (a) FO-4 (b) FO-9A-1

tant phase) and decreased to the initial level typically within $100 \mathrm{msec}$ (decay phase). Among the five gas injection experiments in different flight configurations (Functional Objectives; FO-4, 6-1, 6-2, 9A-1, 9A-2), the enhancement of the Langmuir current by the gas injection was clearly observed three times (FO-4, 6-1, 9A-1). They are summarized in Table 1, together with the experimental conditions. The Langmuir probe was operated in sweep mode in FO-6 and both 
Table 1. Summary of gas injection experiments.

\begin{tabular}{|c|c|c|c|c|c|}
\hline $\mathrm{FO}=$ & 4 & $6-1$ & $6-2$ & $9 A-1$ & $9 A-2$ \\
\hline Altitude (km) & $254-253$ & $254-253$ & 250 & $253-254$ & 251 \\
\hline Orbiter Velocity ( $\mathrm{km} / \mathrm{sec})$ & 7.5 & 7.5 & 7.5 & 7.5 & 7.5 \\
\hline \multirow[t]{2}{*}{ Injection Angle to Orbiter Velocity (deg) } & $82-80$ & $116-118$ & 135 & 99 & $136-135$ \\
\hline & Ram & $\begin{array}{c}\text { Wake } \\
\text { (Near Ram) }\end{array}$ & Wake & $\begin{array}{c}\text { Wake } \\
\text { (Near Ram) }\end{array}$ & Wake \\
\hline Strength of Magnetic Field (Gauss) & $0.36-0.45$ & $0.24-0.33$ & $0.30-0.36$ & $0.49-0.37$ & 0.26 \\
\hline Injection Angle to Magnetic Field (deg) & $64-68$ & $123-113$ & $131-112$ & $70-51$ & $41-56$ \\
\hline Background Pressure (Torr) & $1.2 \times 10^{-6}$ & $1.1 \times 10^{6}$ & (fluctuated) & $1 \times 10^{-6}$ & $1 \times 10^{-6}$ \\
\hline Pressure during Gas Injection (Torr) & $2.8 \times 10^{-6}$ & $2.8 \times 10^{-6}$ & (fluctuated) & $2.8 \times 10^{-6}$ & $2.3 \times 10^{-6}$ \\
\hline Background Plasma Density (/cc) & $\begin{array}{l}\text { less than } \\
4 \times 10^{3}\end{array}$ & $\begin{array}{l}\text { less than } \\
4 \times 10^{3}\end{array}$ & $\begin{array}{l}\text { less than } \\
4 \times 10^{3}\end{array}$ & $1 \times 10^{4}$ & $\begin{array}{c}\text { less than } \\
4 \times 10^{3}\end{array}$ \\
\hline Enhanced Plasma Detection & strong & weak & no & strong & weak * \\
\hline VLF Wave Detection & strong & weak & no & strong & strong * \\
\hline
\end{tabular}

* detected for a few shots among 45 shots.

in fixed and sweep modes in FO-4 and -9A.

The main features of the plasma enhancement are summarized as;

1. The current-voltage curve obtained by the Langmuir probe coincides with the characteristics for plasma, as is shown in Fig. 4. The sampling rate of the data acquisition of the current does not allow us to obtain the accurate plasma

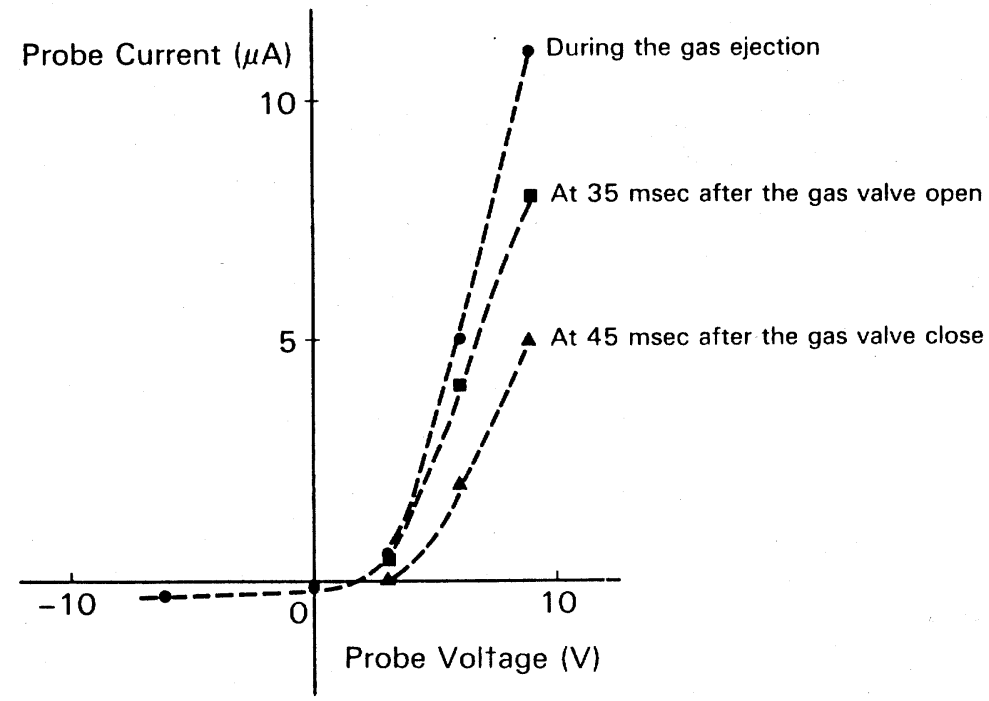

Fig. 4. The current-voltage characteristic measured by the Langmuir probe for the plasma detected when the gas is injected. It is depicted for the rising phase, constant phase and decay phase. 
temperature, but if assuming that the electron temperature was typically $1000^{\circ} \mathrm{K}$, the plasma density amounted to $1.5 \times 10^{6} / \mathrm{cc}$ at most.

2. The Langmuir current at a fixed bias voltage rose almost in proportional to the pressure measured by the gauge, as shown in Fig. 5.

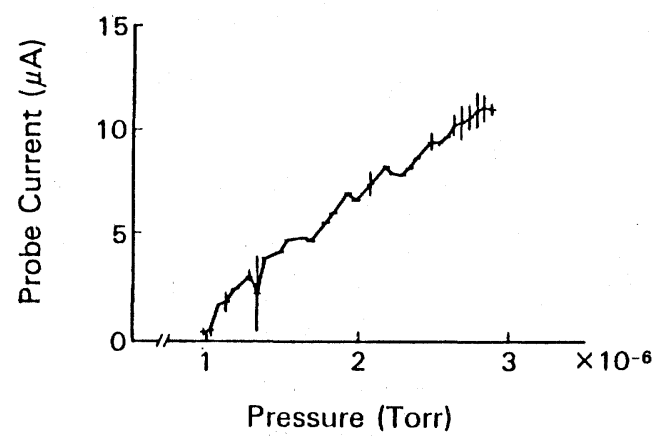

Fig. 5. Relation between the probe current biased at $9 \mathrm{~V}$ and gas pressure in the rising phase. The current is almost proportional to the gas pressure.

3. The rising time of the probe current in FO-4 was shorter than that of the pressure. In this case, a small jump of the current was observed just when the gas density started to decrease (Fig. 3(a)). In FO-9A-1, the rising time of the probe current coincided with the pressure and no current jump was observed (Fig. 3(b)).

4. VLF wave signal was occasionally detected accompanying with the plasma enhancement as shown in Fig. 6. The intensity was usually maximum during the decay phase.

\section{Possible Mechanism for the Plasma Enhancement}

The flight configuration of the orbiter seems to be very important to this effect, as is evident from Table 1. The direction of the gas injection was into RAM or near RAM when the plasma enhancement was detected, while it was into WAKE when the enhancement was small or not detected. The attitude of the orbiter with respect to the velocity vector is specifically drawn in Fig. 7 for each configuration. This fact indicates that the space plasma drifting with respect to the gas plume played an essential role for the plasma enhancement observed by the Langmuir probe during the gas injection. This effect has never been observed in the ground laboratory experiment using the same flight hardwares in a large space chamber.

Two processes can be considered for the plasma enhancement measured by the Langmuir probe; ionization of the gas molecules by hot electrons produced 


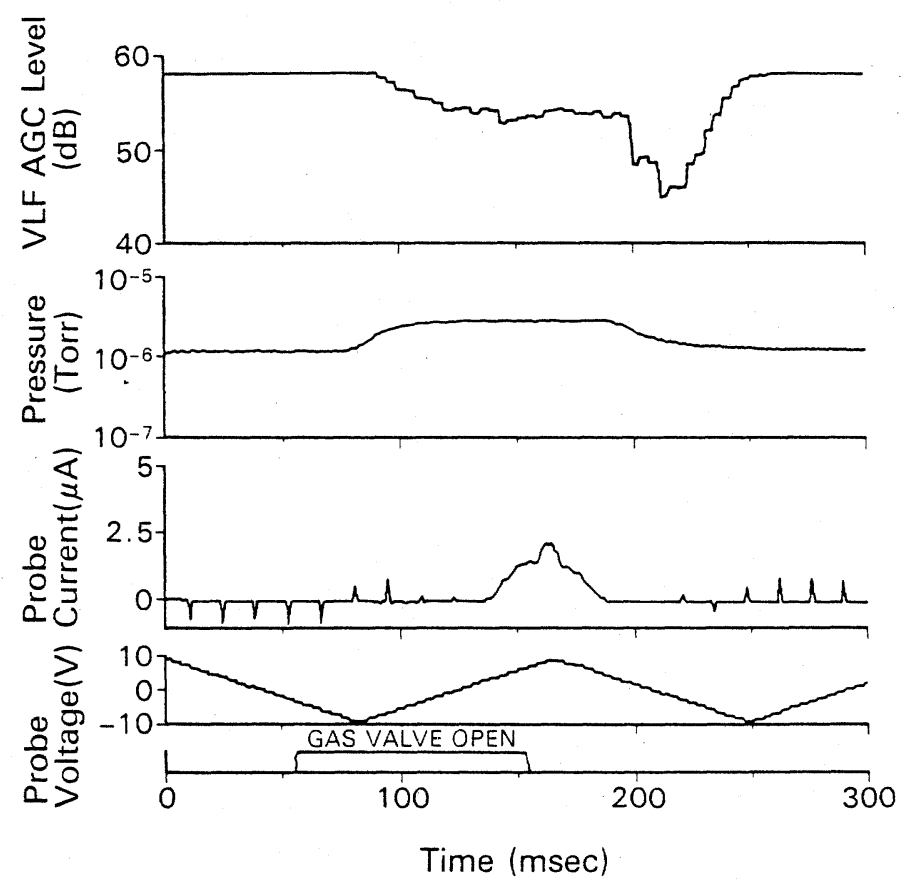

Fig. 6. VLF wave signals observed in FO-6-1. The probe bias is changing from $-9 \mathrm{~V}$ to $+9 \mathrm{~V}$ during $84 \mathrm{msec}$.

by a wave-particle interaction or a collisional interaction between the ionospheric plasma and the gas plume. In the former process, plasma is produced additionally, while plasma is not produced in truth in the latter process.

The possibility of the plasma production by the critical velocity ionization has been discussed by MöBIUS et al. (1979) and PAPAdopoulos (1983) in relation to gas injection experiment in space. However, the critical ionization velocity for nitrogen is calculated to be $10.4 \mathrm{~km} / \mathrm{sec}$, which is rather faster than the orbiter velocity $(7.5 \mathrm{~km} / \mathrm{sec})$. In FO-9A-1, the plasma enhancement was observed even when the orbiter velocity perpendicular to the magnetic field was less than $6 \mathrm{~km} / \mathrm{sec}$. Also the enhancement of the light emission which is incidental to the critical velocity ionization was not detected by the photometer during the gas injection. Then there is very little possibility that the plasma enhancement is attributed to the critical velocity ionization.

The scattering of the ionospheric ions by the gas molecules is more likely responsible for the enhanced plasma detection. Since the Langmuir probe is located near the bottom of the pallet, it is usually inside the wake and the ionospheric plasma scarcely comes into the probe due to the large Mach number of the orbiter velocity. However, when the high dense gas plume is injected into the plasma stream moving relative to the orbiter, some of plasma ions interact with the 
FO-4

FO-6-1

FO-6-2

FO-9A-1
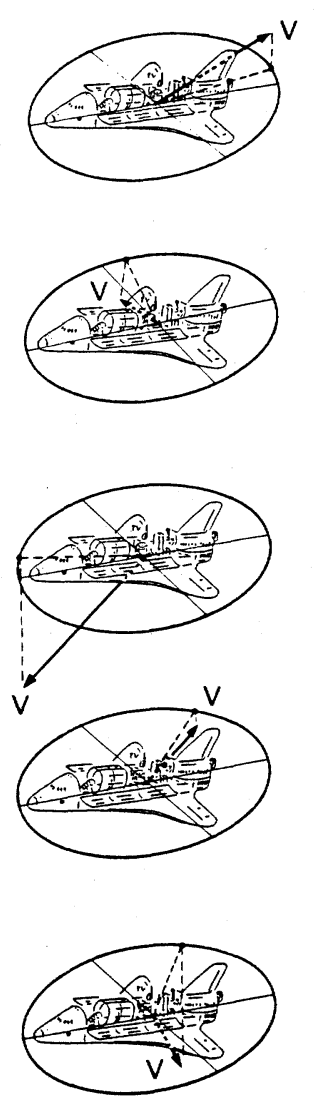

\section{FO-9A-2}

Fig. 7. The attitude of the orbiter for the five gas injection experiments. The gas was injected upwards perpendicularly to the circle. The enhancement of plasma density was detected only when the gas was injected into the RAM or near RAM direction.

gas molecules and are scattered towards the plasma probe inside the wake.

Here, the density of the scattered plasma towards the Langmuir probe is calculated under a simplified configuration, neglecting the effect of the local wake by the surrounding instruments. In the calculation, the following are assumed:

1. The scattering of the plasma ions by the gas molecules is isotropic.

2. The scattered plasma diffuses parallel to the magnetic field.

3. Secondary interaction between the scattered ions and the gas molecules is neglected.

The condition for the detection of the scattered plasma by the plasma probe is that the magnetic field line connecting to the probe passes through the gas plume outside the wake, as is illustrated in Fig. 8. The scattering rate of the plasma to the plasma probe from a small cylindrical segment $(\mathrm{dL})$ with unit 

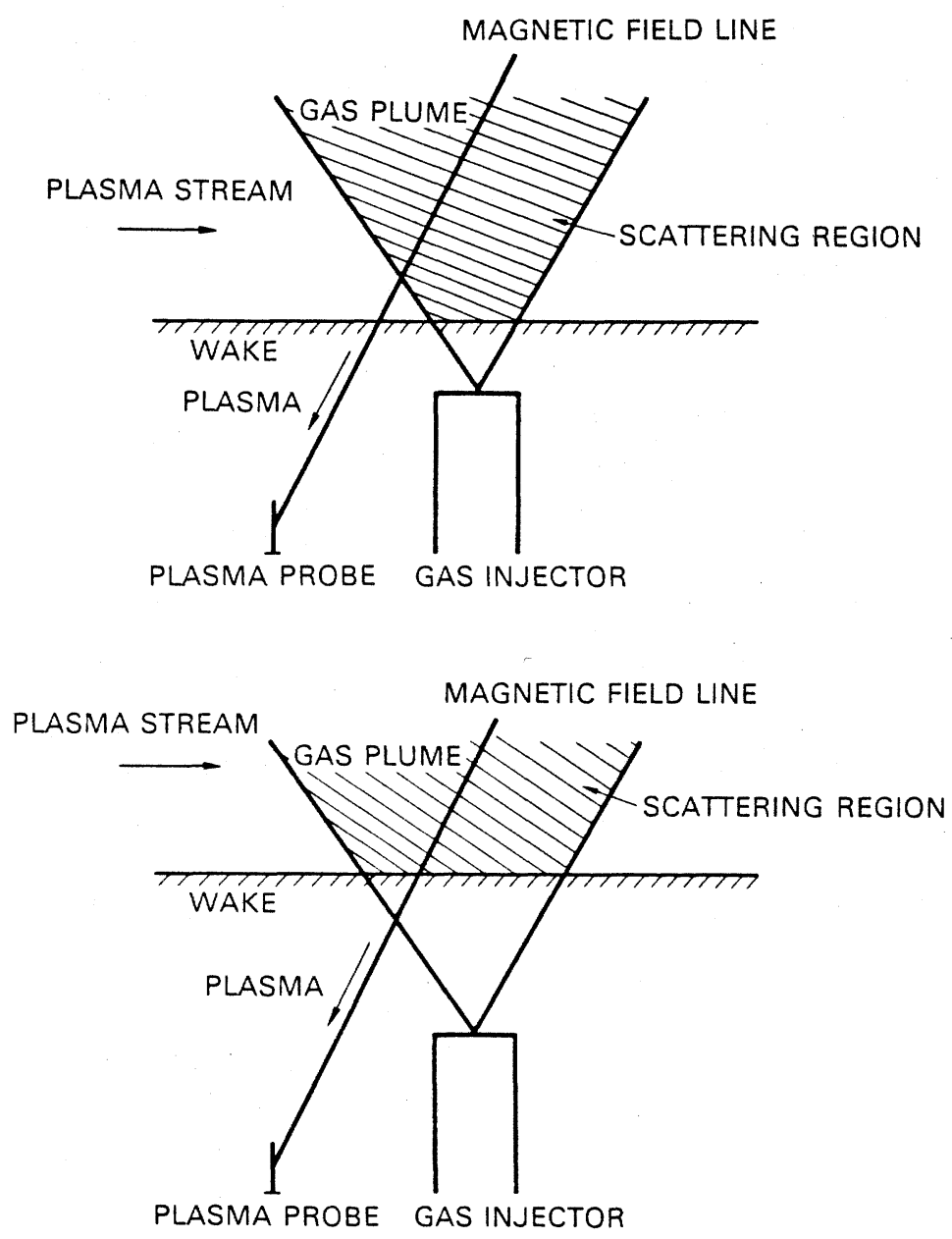

Fig. 8. Configuration of the gas plume and Langmuir probe for the scattering plasma reaching the probe. There are two cases; the intersection of the magnetic field line and the cone of the gas plume is inside or outside the wake.

cross sectional area and with its axis parallel to the magnetic field line is expressed as;

$$
\mathrm{d} I=I_{\mathrm{p}} n_{\mathrm{g}}(r) \sigma \sin \theta \mathrm{d} L / 2
$$

here,

$I_{\mathrm{p}}$ : plasma flux density,

$n_{\mathrm{g}}(r)$ : gas density at $\mathrm{r}$ from the exit of the gas injector,

$\sigma$ : cross section of plasma-gas molecule interaction, 
$\theta$ : angle between the geomagnetic field and plasma stream.

The plasma density at the probe is obtained by integrating (1) along the magnetic field line intersecting the gas plume exposed in the plasma stream as;

here,

$$
n_{\mathrm{p}}=\int n_{0}\left(v_{\text {orb }} / v_{\text {ion }}\right)(\sin \theta / 2) \sigma n_{\mathrm{g}}(r) \mathrm{d} L
$$

$$
n_{\mathrm{g}}(r)=I_{\mathrm{g}} /\left(r^{2} \Omega v_{\mathrm{gas}}\right)
$$

$n_{0}$ : . background plasma density,

$v_{\text {orb}}$ : orbiter velocity,

$v_{\text {ion: }}$ velocity of scattered plasma,

$I_{\mathrm{g}}$ : gas flux from the gas injector,

$\Omega$ : solid angle of gas ejection cone,

$v_{\text {gas: }}$ gas velocity.

The numerical calculation for Eq. (2) is carried out for each flight configuration. As shown in Fig. 9, the results of the calculation are in approximate agreement with the measurements when we assume $v_{\text {ion }}=1000 \mathrm{~m} / \mathrm{sec}, \sigma=2 \times 10^{-21} \mathrm{~m}^{2}$ and $n_{0}=5 \times 10^{10} / \mathrm{m}^{3}$. Since oxygen atom is the major component of the space plasma at the orbital height, three processes can be considered for the collisional interaction with the nitrogen molecules:

$$
\begin{aligned}
& \mathrm{O}^{+}+\mathrm{N}_{2} \rightarrow \mathrm{O}^{+}+\mathrm{N}_{2} \text { (elastic collision), } \\
& \mathrm{O}^{+}+\mathrm{N}_{2} \rightarrow \mathrm{NO}^{+}+\mathrm{N} \text { (ion-atom interchange) } \\
& \mathrm{O}^{+}+\mathrm{N}_{2} \rightarrow \mathrm{N}_{2}^{+}+\mathrm{O} \text { (charge exchange) }
\end{aligned}
$$

Among them, the cross section of charge exchange is much smaller than the assumption in the above calculation when the relative velocity is $7.5 \mathrm{~km} / \mathrm{sec}$.

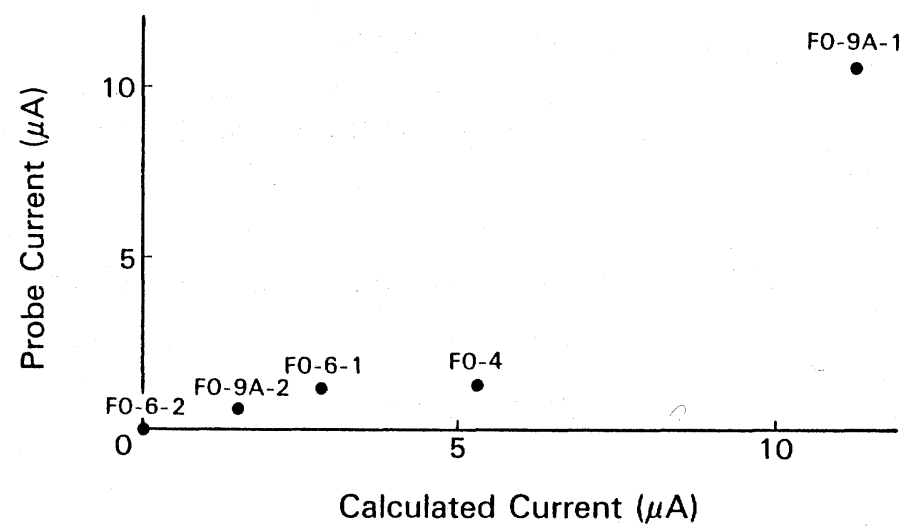

Fig. 9. Calculated probe current for each configuration is compared with the observation. $v_{\text {ion }}=1000$ $\mathrm{m} / \mathrm{sec}, \sigma=2 \times 10^{-21} \mathrm{~m}^{2}$ and $n_{0}=5 \times 10^{10} / \mathrm{m}^{3}$ are assumed in the calculation. 
Both the elastic collision and ion-atom interchange (ALBRITTON et al., 1977) can provide a close value for the cross section used in the calculation.

The opening time of the gas valve is estimated as $30 \mathrm{msec}$ from the signal of the pressure gauge. Since the main contribution to the integration in Eq. (2) is by the segment around the intersection of the magnetic field line and the gas plume exposed in the plasma stream, the increasing time of the plasma density for a constant gas injection is characterized by (a distance of the intersection from the gas exit) $/ v_{\text {gas }}$. In case of FO- 4 and $9 \mathrm{~A}-1$, the opening time of the gas valve is much larger than that characteristic time, then the rising time of the Langmuir current is dominated by the opening time of the gas valve. In the model, the probe current is proportional to $I_{\text {gas }}$, which is consistent to the experimental result that the Langmuir current is proportional to the gas density measured by the gauge.

The reason for the short rising time of the probe current and the existence of the current jump appeared just at the start of the pressure decay in FO-4 can be explained by the effect of the secondary collision between the scattered ions and the gas molecules which is not considered in the present model. The secondary collision suppresses the diffusion of the scattered plasma to the probe during the gas injection, which results in the short rising time. At the start of the gas decreasing, the produced plasma can diffuse to the probe with less interaction with the gas molecules which results in the temporal increase of the probe current. Actually, in the FO-4 configuration, the path from the region of the plasma production to the probe is relatively larger than that of FO-9A-1. Corresponding to this, the ratio of the observed current to the calculated one in Fig. 9 is smaller in FO-4 than in FO-9A-1.

VLF wave was generally observed in the FOs in which the enhanced plasma current was detected, though the intensity was not proportional to the probe current. VLF waves can not be generated in the collisional interaction described above. The excitation of the VLF waves suggests that a wave-particle interaction did occur by the gas injection which will be analyzed elsewhere. However, the dominant process responsible for the enhancement of the probe current is most likely attributed to the scattering of the ionospheric plasma by the gas injection.

\section{Conclusion}

The enhancement of the plasma density during the gas injection observed in SEPAC Spacelab-1 experiment is studied. The mechanism for the plasma enhancement at the plasma probe has been explained by the collisional interaction between the gas molecules and ionospheric ions which relatively drift with the orbital velocity. The space plasma scattered by the gas plume diffused towards the plasma probe located inside the wake, which enhanced the probe current during the gas injection. 
The authors are very grateful for the collaboration of the NASA and ESA Spacelab-1 team headed by Mr. H. Craft, Drs. R. Chappell and K. Knott. They also wish to thank Drs. M. Nagatomo, K. Ninomiya, M. Ejiri, I. Kudo, O. K. Garriott, Mr. B. B. Baker, and other SEPAC members for promoting the SEPAC project.

\section{REFERENCES}

Albritton, D. L., I. Dotan, W. Lindinger, M. McFarland, J. Tellinghuisen, and F. C. FEHSENFELD, Effects of ion speed distribution in flow-drift tube studies of ion-neutral reactions, J. Chem. Phys., 66, 410-421, 1977.

KATZ, I., D. E. PARKs, D. L. COOKE, and J. R. Lilley, Jr., Polarization of spacecraft generated plasma clouds, Geophys. Res. Lett., 11, 1115-1116, 1984.

Möbius, E., R. W. Boswell, A. PIEL, and D. HenRY, A spacelab experiment of the critical ionization velocity, Geophys. Res. Lett., 6, 29-31, 1979.

Obayashi, T., N. KaWashima, K. Kuriki, M. Nagatomo, K. Ninomiya, S. Sasaki, M. Yanagisawa, I. Kudo, M. Ejiri, W. T. Roberts, C. R. Chappell, D. L. Reasoner, J. L. Burch, W. L. TAYlor, P. M. BAnks, P. R. Williamson, and O. K. Garriott, Space experiments with particle accelerators, Science, 225, 195-196, 1984.

PAPADOPOUlOS, K., Neutral gas plasma interactions and critical ionization velocity phenomena, Text of an invited talk (6A3) presented at the Twenty-fifth Annual Meeting of the Division of Plasma Physics, Los Angeles, CA; 7-11 November 1983.

Sasaki S., N. KaWAshima, K. Kuriki, M. Yanagisawa, T. Obayashi, M. Nagatomo, K. Ninomiya, M. Ejiri, I. Kudo, W. T. Roberts, C. R. Chappell, D. L. Reasoner, J. L. BurCh, W. L. TAYlor, P. M. BANKS, P. R. Williamson, and O. K. GARRiotT, Gas ionization phenomena in SEPAC SPACELAB-1 experiment, ISAS Res. Note RN259, 1984. 